\section{Comparison of intravitreal ranibizumab and bevacizumab treatment for retinopathy of prematurity}

\section{Comparação da injeção intravítrea de ranibizumabe e bevacizumabe para o tratamento da retinopatia da prematuridade}

Dear Editor:

First, we commend the authors for comparing two different anti-VEGFs in the treatment of retinopathy of prematurity. We would like them to address our concerns related to their study. In the study, two patient groups, to which $0.25 \mathrm{mg}$ ranibizumab and $0.625 \mathrm{mg}$ bevacizumab were administered, were compared. It was reported in the study that the recurrences in the earlier period occurred because the half-life of ranibizumab is short and the recurrences in the later period occurred because the half-life of bevacizumab is long ${ }^{(1)}$. In the cases in which bevacizumab was administered, recurrence was observed less frequently, but it had to be followed-up for longer period of time ${ }^{(1)}$.

In this study, both anti-VEGFs were found to be effective for type 1 ROP. It appears that ranibizumab was administered to all of the zone 1 ROP patients in the study, as described in table 1, and bevacizumab was not used. We would like to know what criteria were used for medicine administration choices for the zone 1 cases. On the other hand, when the cases in which bevacizumab was adminis- tered were compared with the cases in which laser was used, the high myopia rate was significantly lower ${ }^{(2)}$. In a comparable study, a significantly higher chance of high myopia was noted in the bevacizumab group than in the ranibizumab group ${ }^{(3)}$. Although the refraction results were not reported in the study, we would like to know if there is a notable characteristic refractive error in terms of high myopia in the cases.

Osman Melih Ceylan', Seyhan Dikçi',

Oğuzhan Genc', Turgut Yılmaz ${ }^{1}$

Submitted for publication: February 23, 2016 Accepted for publication: May 15, 2016

Inonu University, Department of Ophthalmology, Malatya,Turkey. Funding: No specific financial support was available for this study.

Disclosure of potential conflicts of interest: None of the authors have any potential conflicts of interest to disclose.

Corresponding author: Osman Melih Ceylan. Department of Ophthalmology, Inonu University Malatya - Turkey - E-mail: drmelihceylan@yahoo.com.tr

\section{REFERENCES}

1. Erol MK, Coban DT, Sari ES, Bilgin AB, Dogan B, Ozdemir OT, et al. ZO. Comparison of intravitreal ranibizumab and bevacizumab treatment for retinopathy of prematurity. Arq Bras Oftalmol. 2015;78(6):340-3.

2. Harder BC, Schlichtenbrede FC, von Baltz S, Jendritza W, Jendritza B, Jonas JB. Intravitreal bevacizumab for retinopathy of prematurity: refractive error results. Am J Ophthalmol. 2013;155(6):1119-24.e1.

3. Chen SN, Lian I, Hwang YC, Chen YH, Chang YC, Lee KH, et al. Intravitreal anti-vascular endothelial growth factor treatment for retinopathy ofprematurity: comparison between Ranibizumab and Bevacizumab. Retina. 2015r;35(4):667-74.

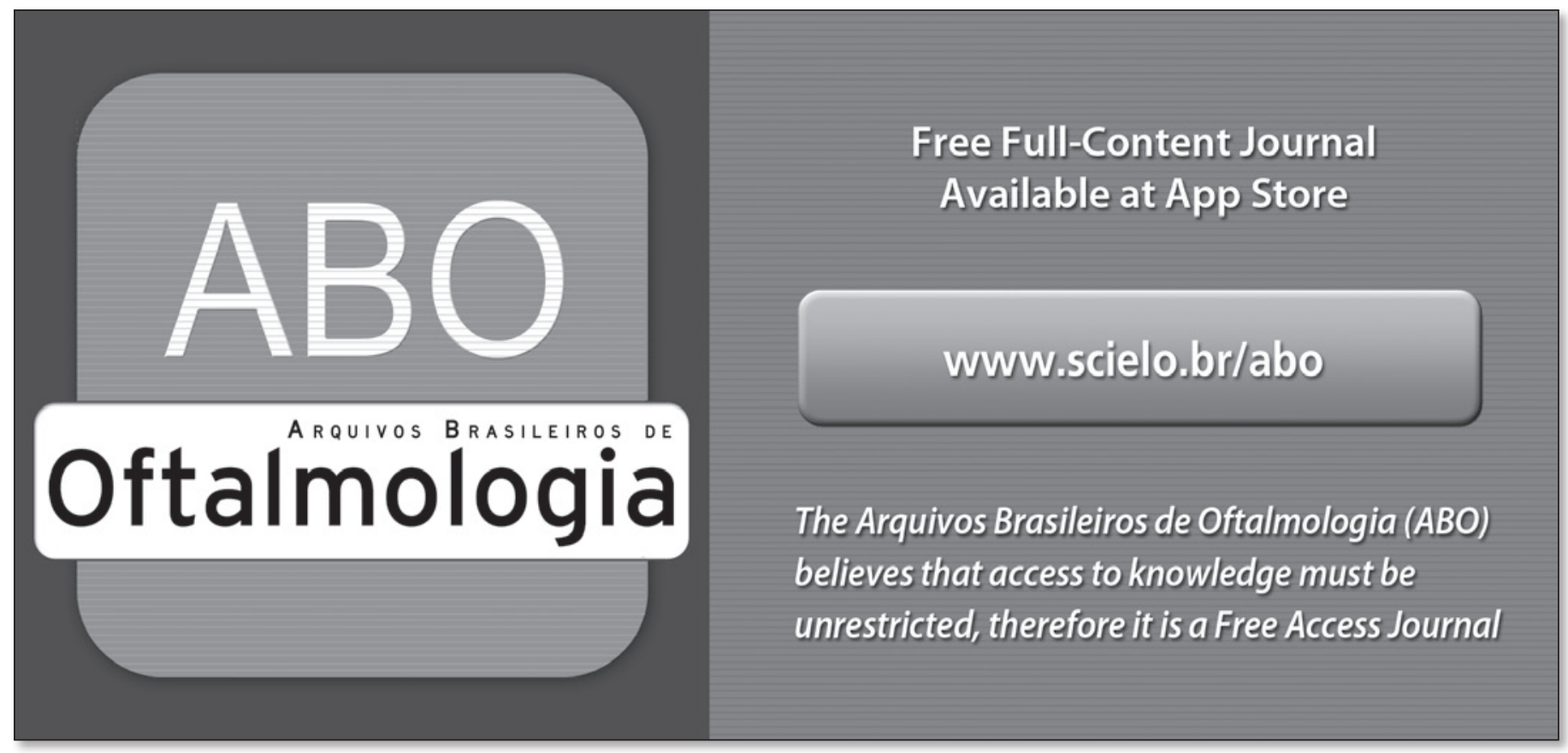

